\title{
Outer membrane protein folding from an energy landscape perspective
}

\author{
Bob Schiffrin, David J. Brockwell ${ }^{*}$ and Sheena E. Radford ${ }^{*}$
}

\begin{abstract}
The cell envelope is essential for the survival of Gramnegative bacteria. This specialised membrane is densely packed with outer membrane proteins (OMPs), which perform a variety of functions. How OMPs fold into this crowded environment remains an open question. Here, we review current knowledge about OMP folding mechanisms in vitro and discuss how the need to fold to a stable native state has shaped their folding energy landscapes. We also highlight the role of chaperones and the $\beta$-barrel assembly machinery (BAM) in assisting OMP folding in vivo and discuss proposed mechanisms by which this fascinating machinery may catalyse OMP folding.
\end{abstract}

\section{The outer membrane protein folding problem}

More than 50 years of work on the folding pathways of water soluble proteins has yielded a plethora of detailed insights into the conformations visited by polypeptides along complex routes to their native conformations. These include the structural and energetic properties of transition states [1-4], partially folded intermediates [5-7], and lowly-populated 'invisible' states [8]. The role of molecular chaperones in assisting folding and preventing aggregation has also been studied extensively $[9,10]$, and powerful biophysical and structural methods are beginning to reveal how water soluble proteins fold in the crowded cellular environment [11], including during their synthesis on actively translating ribosomes [12-14]. By contrast, understanding the folding energy landscapes of membrane proteins (MPs) has lagged behind those of water soluble proteins, despite recent important progress. Here, we focus on outer membrane proteins (OMPs) from Gram-negative bacteria (for discussions of $\alpha$ helical MPs see [15-22], and elsewhere in this issue).

\footnotetext{
* Correspondence: d.j.brockwell@leeds.ac.uk; s.e.radford@leeds.ac.uk Astbury Centre for Structural Molecular Biology, School of Molecular and Cellular Biology, Faculty of Biological Sciences, University of Leeds, Leeds LS2 9JT, UK
}

(c) Radford et al. 2017 Open Access This article is distributed under the terms of the Creative Commons Attribution 4.0 International License (http://creativecommons.org/licenses/by/4.0/), which permits unrestricted use, distribution, and reproduction in any medium, provided you give appropriate credit to the original author(s) and the source, provide a link to the Creative Commons license, and indicate if changes were made. The Creative Commons Public Domain Dedication waiver (http://creativecommons.org/publicdomain/zero/1.0/) applies to the data made available in this article, unless otherwise stated.
OMP assembly in vivo is complicated by the requirement to fold in an asymmetric lipid bilayer, as well as the need to cross the inner membrane and periplasmic space following synthesis in the cytosol. We highlight how these requirements impose constraints on the evolution of OMP sequences and how this influences the thermodynamics and kinetics of OMP folding. Finally, we discuss how cellular proteins may sculpt the folding energy landscape of OMPs to increase the rate and/or efficiency of folding and assembly in vivo.

\section{Evolutionary constraints on OMP sequences}

For proteins to fold stably into the hydrophobic environment of a biological membrane their structure must fulfil a number of energetic requirements including: (1) the hydrogen bonding potential of their polar backbone carbonyl and $\mathrm{NH}$ groups must be mostly satisfied [23] to offset the energetic cost of peptide bond burial ( $1.2 \mathrm{kcal} / \mathrm{mol}$ [24]); and (2) the amino acid side chain groups in contact with the acyl chains of the lipid bilayer must be predominantly hydrophobic. The secondary structures of $\alpha$-helical and $\beta$-barrel membrane proteins allow them to meet these requirements in different ways $[25,26]$. The residues within each helix in $\alpha$-helical MPs make backbone hydrogen bonds, allowing the separate insertion of helices into the membrane bilayer which can subsequently associate laterally to form their final native structure [27]. By contrast, $\beta$-barrel OMPs form cylindrical structures by making hydrogen bonds between residues in different $\beta$-strands, potentially far from each other in sequence [28].

Despite their sometimes complex topology, OMPs are able to fold spontaneously in vitro from their denatured states in urea or guanidinium chloride into detergent micelles or lipid bilayers [29-33] in the absence of cellular factors. This observation is consistent with Anfinsen's findings for the water soluble protein ribonuclease A that all the information for folding is contained within the amino acid sequence [34]. OMPs are structurally and functionally diverse $[35,36]$, with those of known 
structure containing 8-26 membrane-embedded $\beta$ strands in their native state $[35,37]$ (Fig. 1). Larger $\beta$ barrel proteins can be formed by the assembly of monomeric subunits, such as CsgG (9 subunits, $36 \beta$-strands) $[38,39]$ and GspD (15 subunits, at least $60 \beta$-strands) $[40,41]$. The $\mathrm{OM}$ of Gram-negative organisms is an asymmetric bilayer consisting of inner and outer leaflets formed from phospholipid and lipopolysaccharide (LPS), respectively, densely packed with proteins (protein:phospholipid:LPS ratio of 5:1:1 $(w / w)[42,43])$. The requirement for OMPs to fold into this crowded membrane leads to significant pressures on the evolution of OMP sequences. These constraints can be placed broadly into two categories: (i) sequence requirements for OMPs to fold to a stable and functional native state in the $\mathrm{OM}$ (Fig. 2); and (ii) sequence requirements for assisted OMP assembly in vivo (see below). A major constraint is the need for solvation of hydrophobic amino acid side chains in the membrane; hence, the lipid-facing residues in OMPs must be overwhelmingly hydrophobic (Fig. 2(i)) [44], providing the drive for spontaneous membrane insertion [45]. This is reminiscent of the manner by which the hydrophobic effect provides an entropic drive towards the folding of water soluble proteins [46, 47]. Mutations which decrease the hydrophobicity of lipid-facing residues can reduce the kinetics of OMP folding in vivo, leading to premature degradation by the periplasmic protease DegP [48]. Interestingly, the eight-stranded OmpA is able to tolerate substitution of approximately two-thirds of its lipid-facing residues to other hydrophobic residues without losing its ability to fold or to be assembled by in vivo cellular machinery [49].

Recent breakthroughs have been made in measuring the thermodynamic stabilities of OMPs, with data now available for the eight-stranded proteins OmpA [50-54], PagP [55-57] and OmpW [56] and the 12-stranded OmpLA [58] (Fig. 1). These experiments have shown that OMPs are highly stable, with $\Delta \mathrm{G}^{\circ}$ UN values ranging from -3.4 to $-32.5 \mathrm{kcal} / \mathrm{mol}[16,50,56]$, consistent with their common resistance to denaturation by SDS [59-61]. Available evidence suggests that $\Delta \mathrm{G}_{\mathrm{UN}}^{\circ}$ is correlated with the water-to-bilayer transition free energy of the residues that are in contact with the bilayer [56], calculated using the Moon-Fleming hydrophobicity scale [62]. The high stability of OMPs in the OM, compared with their lower free energy of binding to periplasmic chaperones ( -7 to $-13 \mathrm{kcal} / \mathrm{mol}[56,63-65])$, may serve as a sorting mechanism for OMPs in the periplasm [56], with the free energy of folding providing the driving force for assembly into the OM (note that the periplasm lacks ATP) $[66,67]$. So, by contrast with water soluble proteins, which when folded are often only marginally stable [68], the balance between stability and function is less important for OMPs because of their high thermodynamic stability and high energetic barriers to unfolding [69, 70]. Such features should aid the evolution of new functionality since destabilising mutations that enhance a new function can be readily tolerated [71]. An interesting example of the trade-off between activity and stability has been suggested for the acyltransferase PagP: PagP from Salmonella typhimurium is twofold less stable than that from Escherichia coli in dodecylphosphocholine (DPC) micelles $(-6.5 \mathrm{kcal} / \mathrm{mol}$ and $-10.5 \mathrm{kcal} / \mathrm{mol}$, respectively), but has 15-20-fold greater catalytic activity [72] Interesting examples also exist where the stability gained by completing the hydrogen bonding between $\beta$ strands in the $\beta$-barrel has been sacrificed for functional requirements. This is the case for the $\beta$-barrels of PagP [73], FadL [74] and OmpW [75], whose structures suggest they may undergo opening movements to allow lateral entrance of substrates. Structures of BamA, the major subunit of the BAM complex (see below), revealed incomplete hydrogen bonding between the $\mathrm{N}$ - and $\mathrm{C}$ terminal $\beta$-strands ( $\beta 1$ and $\beta 16$ ) [76-79]. This results in frustration in the native protein, enhanced dynamics in the frustrated residues and increased ruggedness in the folding energy landscape close to the native state [80], the significance of which is not yet fully understood.

OMPs must also tailor their sequences to the local chemical characteristics of the OM. This results in different frequencies of residues at different membrane depths [81]. In particular, the positioning of aromatic residues in native OMP structures shows a strong preference for the membrane-water interface ('aromatic girdle') (Fig. 2(ix)) [81, 82], where they contribute to OMP stability [32, 57, 83]. Charged residues are also favoured at the chemically complex interfacial regions [81], with OMPs obeying a positive-outside rule (i.e. positively charged residues are located predominantly on the extracellular surface of the outer membrane; Fig. 2(vi)) [84], in contrast to the 'positive-inside' rule observed for $\alpha$-helical MPs (i.e. basic residues are enriched on the cytoplasmic side of the membrane) [85]. This patterning of charges may help ensure correct orientation of OMPs in the OM. Burial of different residues in the bilayer makes different contributions to OMP stability, and recent evidence suggests that the free energy of partitioning of side chains into membranes is also dependent on the $\beta$-barrel scaffold $[62,86]$. Computational analysis of the transfer free energies of residues at different membrane depths suggests that OMP orientation within the bilayer is also influenced by the effect of residue position on stability in the asymmetric OM [45]. Consistent with this finding, specific LPS binding sites have been identified for E. coli FhuA (Fig. 2(v)) [87], OprH from Pseudomonas aeruginosa [88] and E. coli OmpF, with the latter being shown to be important for biogenesis [89]. Lipidprotein interactions are also important for hydrophobic 


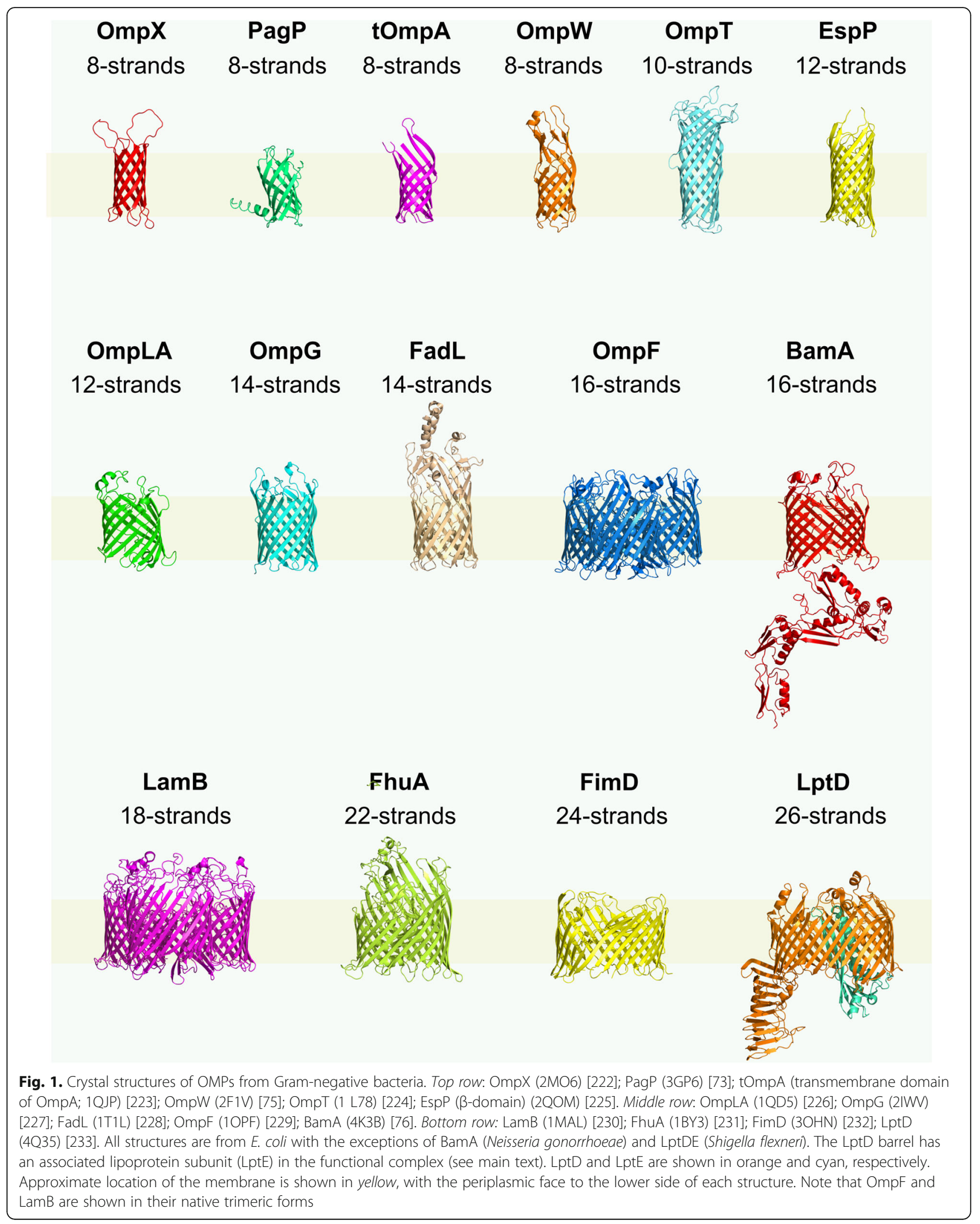




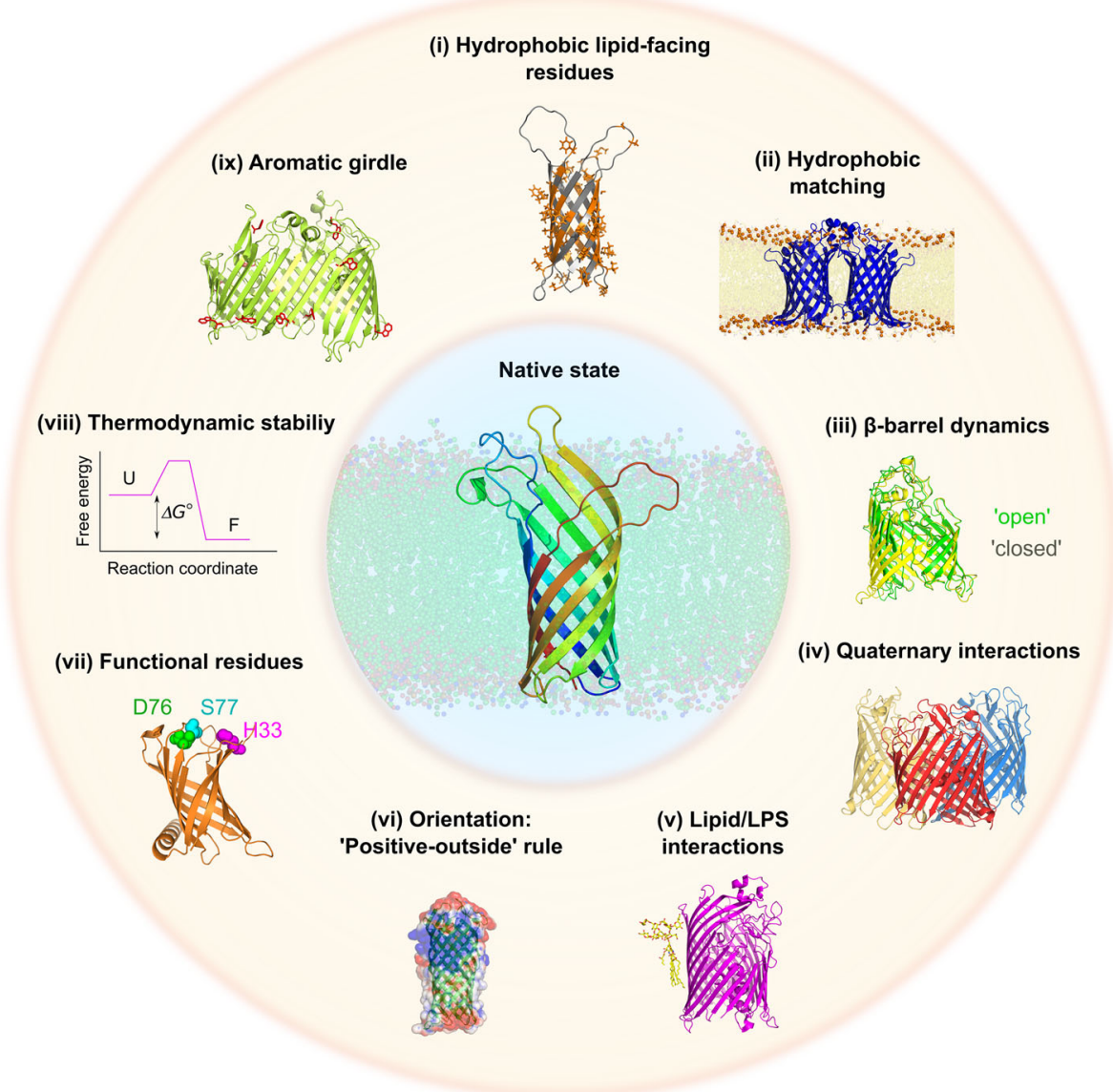

(i) Hydrophobic lipid-facing

residues

Fig. 2. Requirements for OMPs to fold to a stable and functional state. Clockwise from top: (i) OmpX (2MO6 [222], grey) —hydrophobic residues are shown as orange sticks; (ii) OmpLA (1QD6 [226], blue) in a dimyristoylphosphatidylethanolamine (DMPE; diC 14:0P) bilayer (from [234]); (iii) alignment of BamA $\beta$-barrel structures in the 'lateral open' (5D0Q [78], green) and 'lateral closed' (5D00 [78], yellow) states; (iv) OmpF (2OMF [229]) - monomers in the trimeric structure are shown in red, yellow and blue; (v) FhuA (1FI1 [235], pink) - bound LPS is shown as yellow sticks; (vi) OmpT (1178 [224], green cartoon) - regions of red and blue represent areas of electronegative and electropositive surface potential (-1 kT/e to $+1 \mathrm{kT} / \mathrm{e})$ and were created using the APBS plugin for PyMOL [236]; (vii) PagP (3GP6 [237], orange) — conserved residues important in enzymatic function, H33, D76 and S77 (pink, green and cyan, respectively), are highlighted; (viii) free energy diagram showing the difference in stability of the folded ( $F$ ) and unfolded (U) states; (ix) LptD (4N4R [37], lime green)-Trp residues are shown as red sticks. The central image shows the transmembrane domain of OmpA (1QJP [223], with mutated residues in the structure replaced with wild-type residues and missing residues in the loops built in using MODELLER [238]) in a DMPE bilayer (taken from [234])

matching (Fig. 2(ii)). Indeed, the average hydrophobic thickness of OMPs, measured by the distance between aromatic girdles in OMP structures $(23.7 \pm 1.3 \AA$ \& [90], closely mirrors that of the OM in simulations [91]. The requirement for specific interactions between neighbouring $\beta$-strands also constrains OMP sequences. Glycinearomatic inter-strand pairings are often found between neighbouring $\beta$-strands in water soluble proteins [92], and are also common in native OMP structures [84]. These may be important for OMP stability [84, 92] and folding [93], as well as having possible functional roles, as shown for autotransporter assembly [94]. Similarly to water soluble proteins, specific residues may be conserved since they form stabilising quaternary interactions
(Fig. 2(iv)), or are required for enzymatic activity (Fig. 2(vii)) or barrel dynamics (Fig. 2(iii)) [95].

\section{Energy landscapes of OMP folding in vitro}

Since the 1980s, experiments, simulations and theory have led to the view that funnel-shaped energy landscapes best represent the mechanisms of protein folding (Fig. 3), with the depth and width of wells in the landscape corresponding to the energy and conformational entropy, respectively [96-98]. The tension between the covalent connection between amino acid residues and the drive to minimise the contact free energy between each atom leads to frustration in the landscape [99]. Frustrated regions in proteins lead to increased 


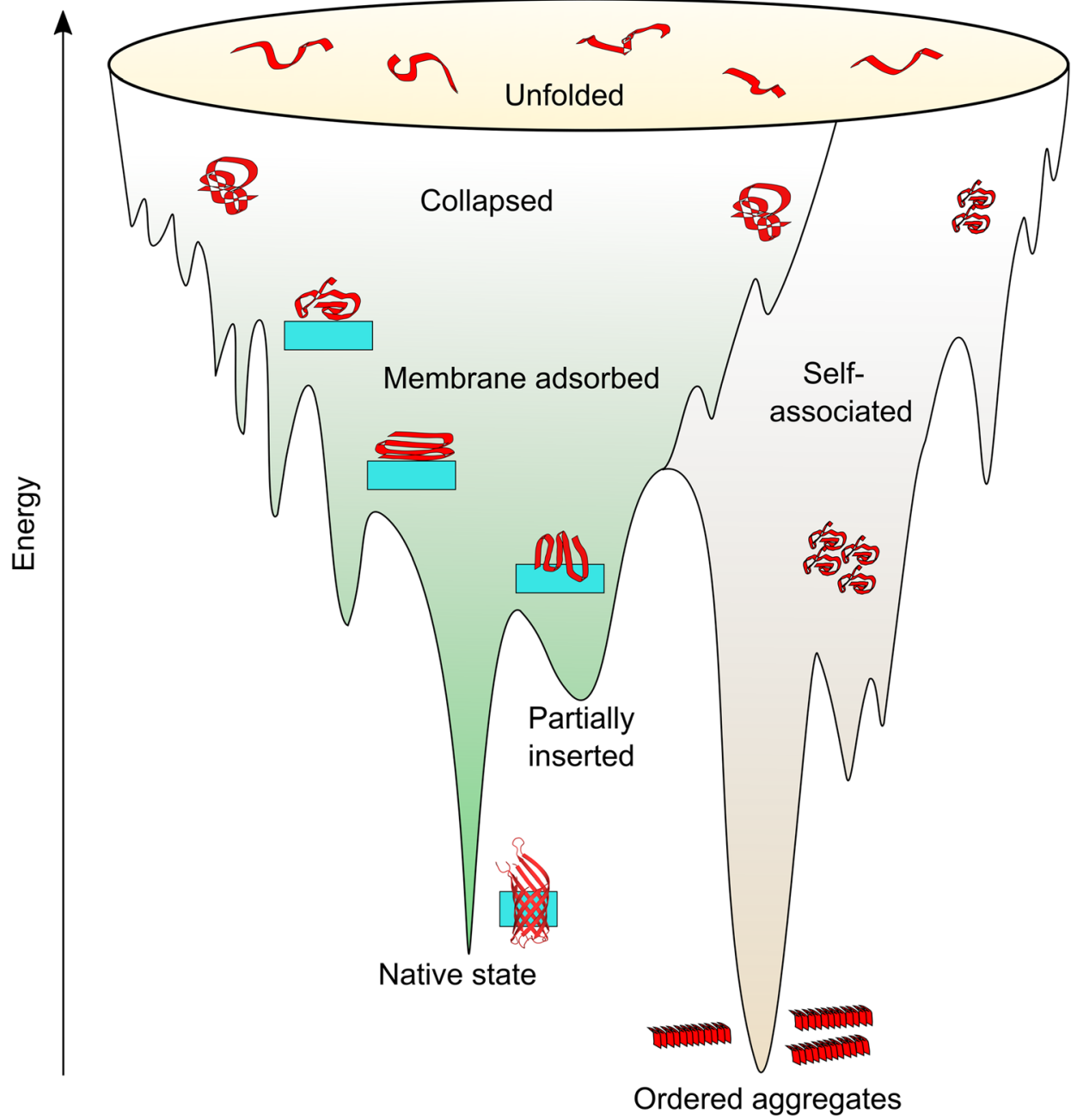

Fig. 3. Hypothetical energy landscape for unassisted OMP folding. The green surface on the left depicts OMP conformations that may be formed en route to the native state. Non-native intramolecular interactions, and/or interactions with the membrane, may lead to ruggedness in the landscape. The surface on the right shows some possible conformations of self-associated OMPs, which may lead to the formation of ordered amyloid-like or disordered aggregates. How folding factors in the cell influence this landscape remains an open question. The OMP polypeptide chain and the membrane are shown in red and blue, respectively

ruggedness in the folding energy landscape, and hence kinetically trapped intermediate states become populated. Over 25 years of work on the folding of OMPs from denaturants into lipid membranes or detergent micelles in vitro has shown that OMPs fold on complex, rugged energy landscapes [29, 30, 100-102]. Early work on OmpA folding in vitro suggested a sequential pathway involving rapid formation of a collapsed state, followed by membrane absorption and possible partial membrane insertion of $\beta$-hairpins [103, 104]. OMP folding may, however, be more complex than a simple sequential route. For example, parallel folding pathways have also been proposed for OmpA [53, 105], FomA [69, 106] and PagP [107], dependent on the folding conditions, such as the $\mathrm{pH}$, the nature of the lipid/detergent and the lipid:protein ratio. Recent, global analysis of the folding kinetics of tOmpA (the transmembrane domain of OmpA) into bilayers of different thicknesses, monitored by circular dichroism (CD) and SDS-PAGE, suggested a sequential model, with detours to off-pathway, misfolded states [108] (named a 'predetermined pathway with optional errors' [109]). This study revealed intermediates with a $\beta$-sheet content higher than that of the native state, which the authors propose may be due to transient $\beta$-strand formation by the extracellular loops on passage across the membrane [108]. Consistent with this view, recent in vivo experiments have shown that the assembly of BamA requires an extracellular loop (L6) to be buried within the newly forming $\beta$-barrel domain [110]. A model in which hydrophilic loops are tucked into folding OMP barrels to assist them across the hydrophobic membrane could also explain 
how lipids are prevented from entering the barrel lumen [110].

Available experimental evidence suggests a concerted mechanism for OMP folding in vitro, in which the final folding step and membrane insertion occur concurrently. Fluorescence quenching experiments showed that all four $\beta$-hairpins of the OmpA barrel cross the bilayer simultaneously [111], and similar kinetics were observed for the formation of OmpA secondary and tertiary structure (observed by CD and cold SDS-PAGE, respectively) on folding into di $\mathrm{C}_{12: 0} \mathrm{PC}$ (DLPC) liposomes [112]. Consistent with this, at least partial structure is formed in all eight $\beta$-strands of PagP in its folding transition state [55]. Further, hydrogen-deuterium exchange (HDX) experiments, which monitored OmpX folding into detergent micelles, found that the rate of hydrogen bond formation was the same between all $\beta$-strands and synchronised with tertiary structure formation [113].

OMPs can also self-associate in their unfolded aqueous states [114], and can populate folded and unfolded dimers and trimers during folding experiments [115], as well as species with higher apparent molecular weights [108], adding further complexity to experiments tracking OMP folding mechanisms. The requirement for OMP sequences to contain alternating polar and non-polar residues that have a high propensity to form ordered aggregates [116] favours the formation of off-pathway, misfolded states. Indeed, similarly to the $\alpha$-helical MP LacY [117], OmpA has been shown to form amyloid-like fibres in vitro in the absence of chaperones [118]. As fibrillar protein species can be associated with cellular toxicity $[119,120]$, this highlights the importance of chaperones in preventing aggregate formation in OMP folding (Fig. 3).

In vitro studies have highlighted the importance of the membrane environment on the kinetics of folding and insertion of OMPs [101, 121]. Bilayers that are more fluid, thinner, contain more unsaturated chains, and have increased curvature stress enhance OMP folding rates and yields [30, 33, 112, 121-124]. Bilayer properties also affect OMP thermodynamic stability; one study found that increasing curvature stress, by substituting $\mathrm{C}_{16: 0} \mathrm{C}_{18: 1} \mathrm{PC}$ (POPC) lipids for $\mathrm{C}_{16: 0} \mathrm{C}_{18: 1} \mathrm{PE}$ (POPE) in liposomes formed from POPC containing a $7.5 \%$ mole fraction of $\mathrm{C}_{16: 0} \mathrm{C}_{18: 1} \mathrm{PG}$ (POPG), increased the stability of OmpA. Conversely, substitution of POPC for shorter chain PC lipids (such as $d i \mathrm{C}_{10: 0} \mathrm{PC}$ ) decreased stability [50]. In vitro studies have also begun to explore the influence of chaperones $[105,125,126]$ and BAM protein components [127-132] on OMP folding in vitro. One key result from these studies is that when E. coli polar native lipids are used to create liposomes, there is a requirement for cellular folding factors to assist OMP folding [33, 127, 128], rationalising the conservation of these folding factors across bacterial species [133-135].

\section{OMP assembly in vivo}

\section{Role of periplasmic chaperones}

Unlike spontaneous folding that is often observed in very dilute solutions [34], protein folding in the cell is challenged by the high concentration of other proteins and macromolecules with which aberrant interactions can be made [136]. This can lead to aggregation, loss of function, and/or the accumulation of toxic species and cell death $[119,137]$. Thus, cells expend considerable effort to maintain unfolded and partially folded proteins in a folding-competent state, and to degrade misfolded, aggregation-prone species $[9,10]$. In the case of OMPs, folding is even more complex since the site of synthesis (the cytosol) is distal to the location of the final folded state in the OM [36]. A network of folding factors is thus required to ensure successful OMP folding and insertion into the OM, which becomes particularly important under stress conditions [138, 139].

Following secretion into the periplasm via the SecYEG translocon in the bacterial inner membrane, OMPs are bound by chaperones, of which the major players in $E$. coli are SurA and Skp [138, 140]. While Skp is a homotrimer with an expandable hydrophobic cavity [141-144], SurA is monomeric and lacks an obvious protein binding site (Fig. 4). The kinetic competition between aberrant OMP self-association and chaperone binding is likely assisted by fast OMP-chaperone association rate constants $\left(\mathrm{k}_{\mathrm{on}} \sim 1-\right.$ $\left.3 \times 10^{8} \mathrm{M}^{-1} \mathrm{~s}^{-1}\right)[64,145]$ and by the availability of a reservoir of unbound chaperones [145]. SurA and Skp help to prevent OMP aggregation [64, 141], but whether they simply stabilise intermediate states on the folding pathway or are more actively involved in dynamically altering the energy landscape of folding to aid productive folding remains unresolved. NMR investigations of Skp-OMP complexes indicate that OMPs are held in an unfolded, compact, and highly dynamic state by multiple weak and transient interactions with Skp that contribute to its high avidity [146, 147], with binding affinities between Skp and OMPs in the low nanomolar range [56, 63]. This high entropy-low enthalpy chaperone-bound state is consistent with the notion that the unusually high thermodynamic stability of OMPs acts as a free energy sink, providing the driving force for release of OMPs from their chaperone-bound states and their folding into the OM $[56,67]$.

Less is known about the conformations of OMPs bound to SurA. As the structure of this chaperone lacks a cage-like cavity (Fig. 4) [148], clients may bind SurA in a more extended conformation, as observed for substrates binding to the chaperone trigger factor [149] and SecB [150], both of which bind OMPs in the cytosol [28]. Similarly to Skp [143], multiple copies of SurA may bind to different regions of unfolded OMPs simultaneously, possibly in a 'beads-on-a-string' fashion $[65,151]$. 


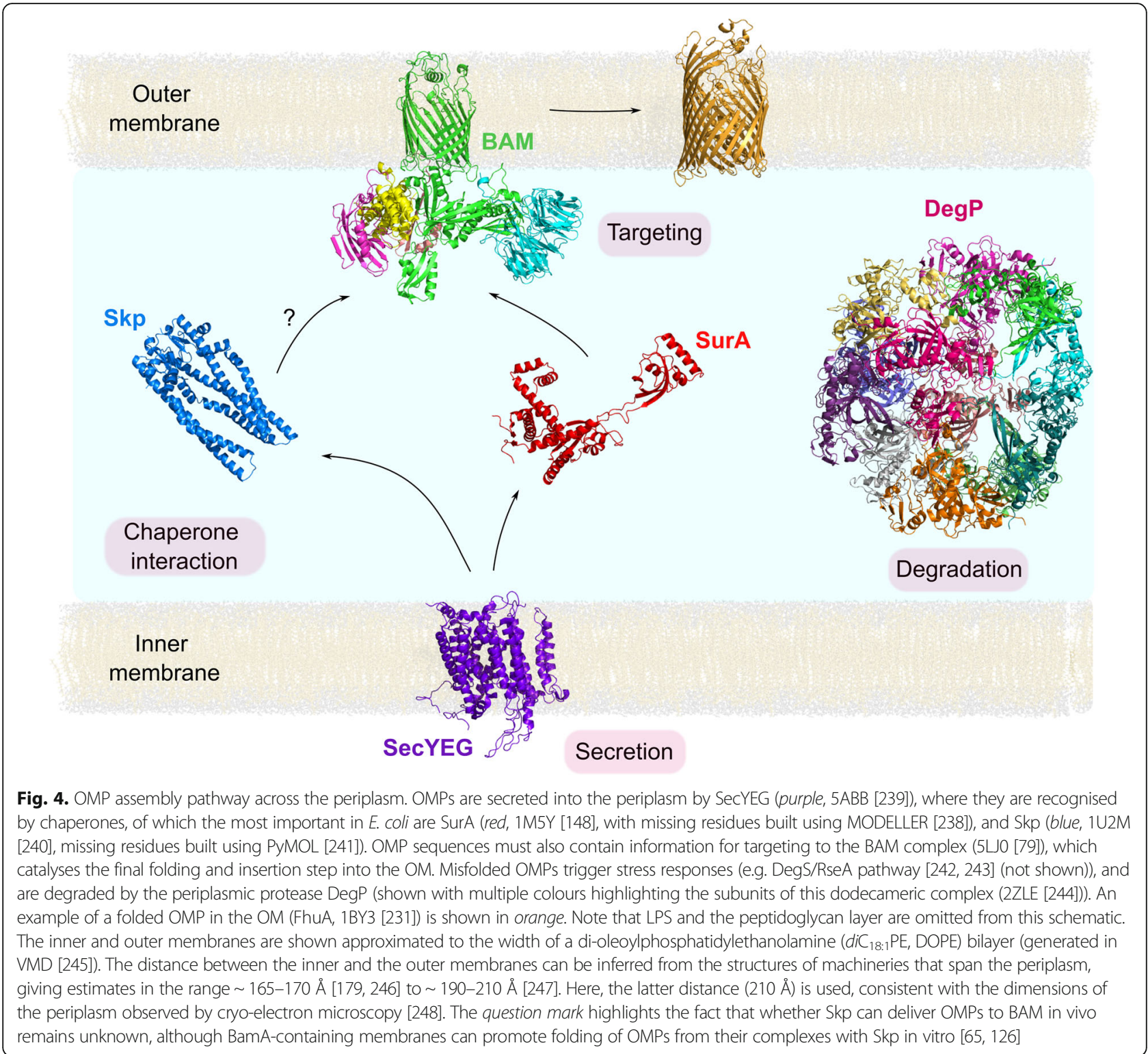

Such extended OMP conformations could prevent the formation of collapsed states, facilitating subsequent folding, as well as disfavouring the formation of aggregates. Consistent with this, mechanical unfolding experiments have shown that SurA can stabilise FhuA folding intermediates and promote their refolding into a bilayer via sequential $\beta$-hairpin units [151]. By contrast, in similar experiments Skp prevented misfolding, but did not assist refolding [151], suggestive of a significant difference in the mode of action of these two chaperones.

SurA is known to have a preference to bind $\mathrm{Ar}-\mathrm{X}-\mathrm{Ar}$ and Ar-Ar motifs (where $\mathrm{Ar}=$ aromatic and $\mathrm{X}=$ any amino acid) that are commonly found in OMP $\beta$-strands $[152,153]$. How these interactions bias the conformational ensemble towards on-pathway folding intermediates remains unresolved. Interestingly, Skp and SurA can bind a broad repertoire of substrates, including a wide range of OMPs [154, 155], as well as water soluble proteins [156-159], including the model protein Im7 in both its native and unfolded states [160]. Unfolded states of OMPs in denaturant have been shown to exhibit non-random coil behaviour [161-163], raising the possibility that OMP-chaperone binding may be entropically favoured by increasing the conformational freedom of the OMP substrate upon chaperone binding [163].

Soluble domains attached to an OMP $\beta$-barrel can also provide chaperone-like behaviour for their attached $\beta$ barrel domains [164]. Such chaperoning may also occur in larger barrels that contain plug domains, such as the 22-stranded Ton-dependent transporters (e.g. FhuA 
(Fig. 1) [165]) and the 26-stranded LptD, which has a separate protein, $\mathrm{LptE}$, residing within the native LptD barrel (Fig. 1) [37]. By providing a surface for nascent $\beta$ sheets to form around, domains within large barrels may also assist OMP folding by preventing misfolding and smoothing the energy landscape for folding [166].

When folding fails misfolded OMPs are recognised, triggering stress responses such as the $\sigma^{\mathrm{E}}$ response (reviewed elsewhere [139, 167-170]). This leads to upregulation of chaperones, and the chaperone/protease DegP, which degrades OMPs in the periplasm (Fig. 4) [140]. In addition, the proteases BepA [171] and YcaL [172] are able to degrade misfolded OMPs that have already engaged with the BAM complex. How OMPs that have successfully folded into the OM are turned over was not well understood since $E$. coli lacks both ATP and a ubiquitin-protease system in the periplasm. Recent exciting experiments using fluorescence microscopy in vivo showed that turnover of OMPs is achieved during cell division, wherein old OMPs are moved to the poles and passed to a fraction of daughter cells following binary fission [173, 174]. Akin to the chaperone network in the cytosol, therefore, in which the concentration of chaperones, foldases and proteases is carefully balanced to sustain life, even under stressful conditions [175], OMP synthesis, folding and degradation are also finely balanced in the bacterial periplasm. Indeed, recent kinetic simulations of OMP biogenesis showed that the flux of OMPs across the periplasm can be modelled as a stochastic process, controlled by the thermodynamics and kinetics of OMP interactions with folding factors and their concentrations [145].

\section{Insertion and folding into the OM}

The headgroups and acyl chain lengths of lipids in the OM provide a significant kinetic barrier for OMP folding [33, $65,127]$. Nature has answered this problem by the creation of an ATP-independent catalyst (the BAM complex) that catalyses folding and insertion of OMPs into the OM (Fig. 4). In E. coli, BAM is a $203 \mathrm{kDa}$ heteropentameric complex (BamA-E) [28, 176-184]. Two BAM subunits are essential: the evolutionarily conserved BamA (itself an OMP; Fig. 1) [185, 186] and the lipoprotein BamD [187]. Deletion of BamB, BamC or BamE, by contrast, leads to varying degrees of $E$. coli growth defects [176].

Nascent OMPs must be recognised by BAM and released from their chaperones before they can fold into the OM. The mechanisms of chaperone release are currently not well understood, but must occur in the absence of ATP, contrasting markedly with the mechanism of action of cytosolic chaperones and chaperonins $[9,10]$. SurA has been found in OM fractions [153] and has been crosslinked to BAM in vivo [188, 189]. By contrast, evidence for a direct interaction between Skp and BAM is lacking
[188], although BamA-containing proteoliposomes promote the folding of Skp-bound OmpA and tOmpA in vitro $[65,126]$. Alternatively, Skp may use electrostatic interactions between its positively charged surface and negatively charged lipid headgroups in the inner leaflet of the OM (phosphatidylglycerol (PG) and cardiolipin [190]) to assist delivery of OMPs directly to the OM $[105,125]$. A conserved sequence at or near the C-termini of OMPs (known as the $\beta$-signal) is important for efficient OMP assembly [191, 192]. It has been suggested that this sequence is involved in targeting OMPs to BAM via interactions with BamD [193, 194] and/or BamA [195], although structural evidence for such a molecular recognition event is still lacking.

How BAM catalyses OMP folding remains a second open question. The presence of BAM in the OM may smooth the OMP folding energy landscape by destabilising trapped intermediates and/or lowering the activation energy of folding. Alternatively, BAM may accelerate folding by changing the structural mechanism of OMP folding such that large energy barriers are avoided. Several models have been proposed for the mechanism of BAM-catalysed OMP folding, including the widely publicised 'BamA-assisted' and 'BamA-budding' models [178, 182] (Fig. 5a, b). The BamA-assisted model proposes that BAM reduces the kinetic barrier to folding by thinning and disordering lipids close to the BamA barrel seam, which facilitates OMP folding and insertion (Fig. 5a). In support of this model, the hydrophobic thickness of BamA is reduced at the $\beta 1-\beta 16$ seam, and molecular dynamics simulations of lipid-embedded BamA showed local membrane thinning and disordering at this region [76]. The creation of membrane defects by maintaining lipids at their transition temperature has also been shown to accelerate OMP folding [196]. Further, BamA alone has been shown to increase OMP folding kinetics in vitro $[65,126,127,132]$, with BamA acting as a more effective catalyst in thicker bilayers [65].

In the BamA-budding model, a sequential pathway is proposed for $\beta$-strand insertion, in addition to membrane priming (Fig. 5b). In this model, the C-terminal $\beta$ hairpin of nascent OMPs is proposed to be threaded into the BamA barrel lumen, triggering lateral opening of the BamA barrel at the $\beta 1-\beta 16$ seam. These unpaired $\beta$ strands of BamA are then envisaged to interact with the nascent OMP via $\beta$-augmentation to form an OMPBamA hybrid barrel. Sequential addition of further OMP $\beta$-strands to this 'super-barrel' occurs until the last strand of the OMP is added, triggering budding of the OMP and restoration of BamA to the closed state for a new folding cycle [178, 197]. A similar hybrid barrel model has been proposed for the assembly of autotransporters by the BamA homologue TamA [198]. There is no direct evidence for the BamA-budding model [181], 
a

\section{BamA-assisted}

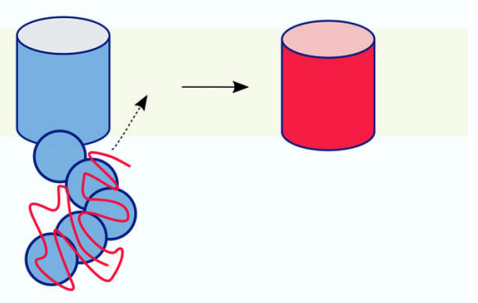

b

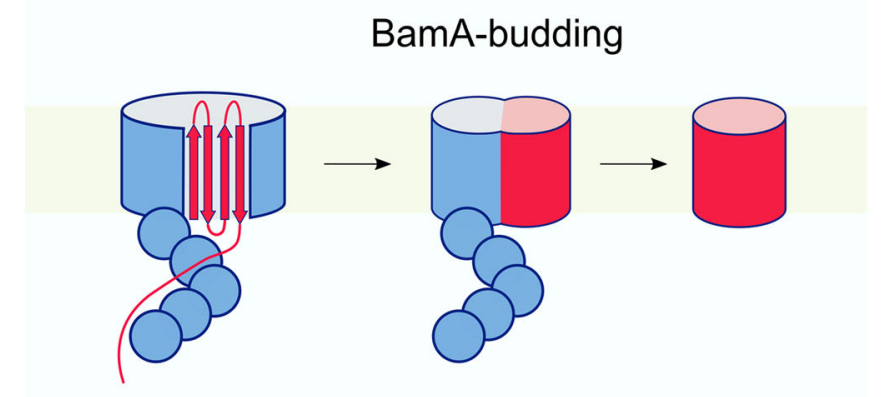

C

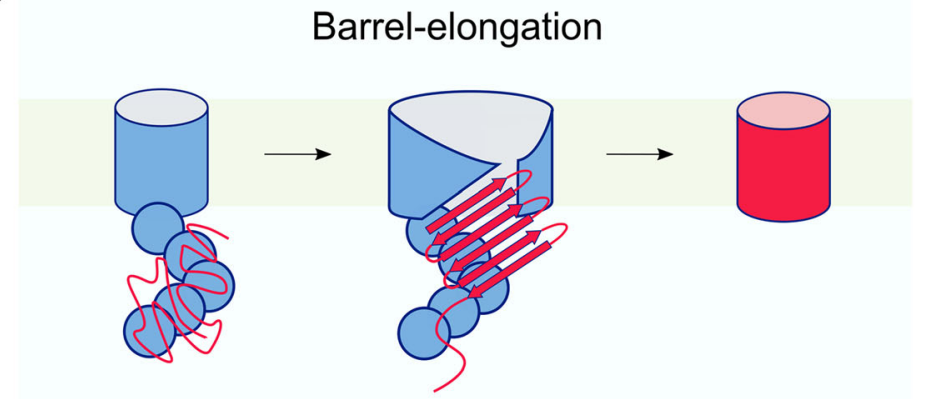

Fig. 5. Possible, currently hypothetical, mechanisms for OMP assembly by the BAM complex. a BamA-assisted. OMPs may fold via a pathway similar to that observed in vitro, with BamA acting as a membrane 'disruptase' to assist folding. b BamA-budding. OMP assembly involves the formation of a hybrid barrel by sequential insertion of $\beta$-strands templated by the $\beta 1 / \beta 16$ strands of BamA. When the final substrate $\beta$-strand has been inserted, the nascent OMP buds off from the BamA barrel to complete folding. $\mathbf{c}$ Barrel-elongation. Interaction of the nascent OMP with the periplasmic BAM region promotes a 'lateral open' BAM state, exposing the $\beta 1$ strand of BamA. BamA $\beta 1$ then templates $\beta$-sheet formation in the nascent OMP, possibly via $\beta$-hairpin units. Folding is completed by concerted OMP insertion and tertiary structure formation, releasing the BamA barrel and allowing BAM to return to the ground state. In all models BamA is involved in destabilising the membrane to aid insertion and folding (not shown). The lipoproteins BamB-E and the chaperone SurA have been omitted for clarity. Note that there is currently little direct experimental evidence to favour one model over another (see main text for more details)

although cross-linking of the BamA $\beta 1-\beta 16$ seam has been shown to be lethal in vivo [80, 197]. However, cross-linking could simply reduce the kinetics of assembly such that cells are no longer viable [182], consistent with the finding that cross-linking the BamA $\beta 1-\beta 16$ seam impairs, but does not prevent, BAM-mediated folding of OmpT in vitro [79].

An alternative model proposed for BAM function suggested tetramerisation of BamA to create a pore that facilitates OMP folding and insertion into the OM [176]. Recently determined BAM structures suggest that such a model is highly unlikely given the potential steric clashes between periplasmic BAM components in the hypothetical tetrameric BAM assembly [77-79, 199]. The finding that a single copy of BAM in nanodiscs containing $E$. coli polar lipid extract is able to assemble the autotransporter EspP also argues against this model [131]. Spatial clustering of BAM complexes may be functionally relevant, however, as BAM has been observed in $0.5 \mu \mathrm{m}$ 'OMP islands' in vivo [173], and genetic experiments suggest that multiple copies of BAM may be involved in the assembly of trimeric porins [200].

Here, we propose an alternative 'barrel-elongation' model for BAM action (Fig. 5c). In this model, a lateralopen state of BamA within the BAM complex is considered the OMP-acceptor, with catalysis of OMP folding involving $\beta$-strand augmentation by the $\beta 1$ strand of BamA. This templating mechanism is analogous to the elongation phase of amyloid self-assembly reactions in which $\beta$-strands are added sequentially to the growing end of amyloid fibrils [119, 201]. In addition, nonspecific aggregation is minimised by folding in a protected environment created by the POTRA domains and BamB-E (see below; Fig. 6a, b). Hence, energetic barriers to folding are proposed to be lowered by templated association of neighbouring $\beta$-strands, consistent with 

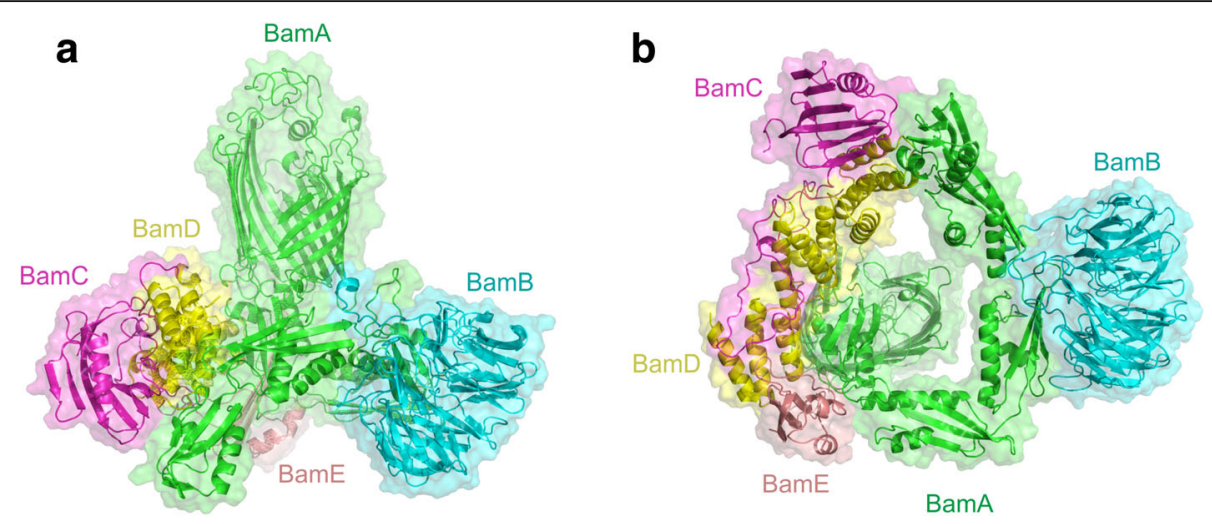

Fig. 6. Cryo-EM structure of the BAM complex. Solution structure of the BAM complex viewed from a the membrane plane, and $\mathbf{b}$ the periplasm. Image created with PyMOL (5LJO [79]). Individual BAM subunits are labelled in different colours, as indicated

in vitro studies that have shown this is the rate-limiting step of unassisted OmpA folding into liposomes [202]. In the proposed model, the formation of OMP $\beta$-sheet structure is hypothesised to begin in the periplasm, in agreement with recent in vivo cross-linking data for an LptDE complex stalled on BAM, which indicated a partially folded LptD barrel in the periplasm [166]. It is possible that successive $\beta$-strands are added to nascent OMPs in $\beta$-hairpin units. This would be consistent with the observations that bacterial OMPs: (1) have short turns at their periplasmic sides, often consisting of only a couple of residues, in contrast with the characteristically long loops on their extracellular sides [35, 203]; (2) have both $\mathrm{N}$ - and $\mathrm{C}$-termini at the periplasmic side of the $\mathrm{OM}$; and (3) all have an even number of $\beta$-strands (Fig. 1) [203]. Further, AFM mechanical unfolding experiments have shown that OMPs can unfold [204, 205] and refold [151] via $\beta$-hairpin units. Whether or not OMP assembly occurs via association of preformed $\beta$ hairpins, however, remains to be seen.

Recent publications reporting structures of BAM in different conformational states have shown that BamB$\mathrm{E}$, together with the $\mathrm{N}$-terminal polypeptide transportassociated (POTRA) domains of BamA, form a ring-like structure in the periplasm (Fig. 6a, b) $[77-79,199]$. Delivery of OMPs by SurA to this region may trigger opening of the BamA barrel to initiate OMP folding. Interactions of nascent OMPs with BamD may be important in this process [206, 207], and dynamics between POTRAs 2 and 3 may also be key to the formation of this active state [208-210]. The BAM periplasmic ring may also provide a cage-like environment, which could be extended by the binding of SurA, to protect elongating OMPs from aberrant interactions in a manner analogous to the 'folding cage' of chaperonins $[9,10]$. The barrel-elongation model, therefore, proposes that the BAM catalytic effect is achieved by: (1) ordered, sequential release of the OMP polypeptide chain from chaperones into the periplasmic BAM folding funnel; (2) catalysis of $\beta$-structure formation in the periplasm by a $\beta$-augmentation interaction with $\beta 1$ of the BamA barrel; and (3) membrane disruption to facilitate concerted insertion and OMP tertiary structure formation. Not all of these catalytic features may be required for the folding of every OMP. For example, templated $\beta$-sheet formation in the nascent OMP by $\beta 1$ of the BamA barrel may not be essential for the assembly of smaller OMPs. While experimental evidence for the barrel-elongation model is lacking, it is consistent with evidence from genetic studies of the BAM complex [206, 207, 211, 212], and with current knowledge of autotransporter assembly [131, 213-218], which is dependent on the BAM complex $[131,216]$. Importantly, a peptide from the OMP FimD (Fig. 1) was recently cross-linked to the TamA barrel, consistent with an interaction with TamA $\beta 1$ via $\beta$-augmentation [219]. Much more work will be needed to provide evidence for or against the different models for BAM activity proposed here (barrel-elongation) and elsewhere (e.g. BamA-assisted, BamA-budding) [176, 181, 182], and to determine whether different mechanisms are utilised for different substrates [200]. In particular, determination of a structure of an intermediate along the BAM-mediated OMP assembly pathway may enable different models to be ruled in or out. Such stalled intermediates were, for example, important in elucidating the mechanism of pilus assembly by the FimD usher [220]. Efforts to obtain the structure of a nascent OMP-BAM complex stalled during folding are a logical next step in the quest to elucidate how this fascinating molecular machine sculpts the OMP folding energy landscape, enabling efficient control of folding and membrane insertion in the absence of ATP.

\section{Towards realistic models of OMP folding energy landscapes}

Great progress has been made in our understanding of how OMPs fold in vitro into bilayers formed from 
different lipids. Similarly, impressive breakthroughs have been made in understanding the factors required for OMP assembly in vivo. How the pathways of OMP folding in vitro compare with those in vivo, however, remains unclear, partly due to a lack of studies that use direct biophysical measurements of OMP folding into physiologically relevant membranes to complement powerful, but indirect, in vivo methods. In vivo, chaperones and the BAM insertase are required to sculpt the OMP folding energy landscape to ensure rapid and efficient folding into the crowded OM. Several models for the mechanism of BAM catalysis of OMP folding have been proposed. All involve membrane destabilisation close to the BamA barrel, with some implicating a more direct role of BamA itself in the formation and stabilisation of OMP folding intermediates. Recent progress in structural analyses of BAM in different conformational states, combined with the development of biochemical and biophysical methods able to track the progress of OMP folding [221], promise to cast new light on the mechanisms of OMP folding, and how OMPs are recognised by their chaperones and released for folding by BAM. Such knowledge will aid the task of bringing our understanding of the folding mechanisms of OMPs to the level of detail achieved for water soluble proteins. It will also allow realistic models of the energy landscapes of OMP folding to be drawn, including how the landscape is modulated by the asymmetric $\mathrm{OM}$ and the BAM complex. Combined with impressive achievements in genetic and cellular studies of OMP assembly, there is no doubt that exciting discoveries will be reported in the years ahead, fuelled by the incentive that such knowledge may lead to the generation of much-needed new anti-bacterial agents that target OMP biogenesis.

\section{Acknowledgements}

BS is funded by the Biotechnology and Biological Sciences Research Council (BBSRC; BB/N007603/1). DJB and SER are supported by the European Research Council under the European Union's Seventh Framework Programme (FP7.20072013/grant agreement number 322408). We thank members of the SER and DJB laboratories and our OMP collaborators, particularly Neil Ranson, Antreas Kalli, Anton Calabrese, Anna Higgins, Jim Horne, Julia Humes and Matt ladanza, for helpful discussions on OMP folding and for their comments during the preparation of this manuscript.

\section{Authors' contributions}

All authors wrote and edited the manuscript. All authors read and approved the final manuscript.

\section{Competing interests}

The authors have no financial and non-financial competing interests.

\section{Publisher's Note}

Springer Nature remains neutral with regard to jurisdictional claims in published maps and institutional affiliations.
Published online: 21 December 2017

References

1. Dill KA, MacCallum JL. The protein-folding problem, 50 years on. Science. 2012;338:1042-6.

2. Englander SW, Mayne L. The nature of protein folding pathways. Proc Natl Acad Sci U S A. 2014;111:15873-80.

3. Fersht AR, Sato S. Phi-value analysis and the nature of protein-folding transition states. Proc Natl Acad Sci U S A. 2004;101:7976-81.

4. Matouschek A, Kellis JT, Serrano L, Fersht AR. Mapping the transition state and pathway of protein folding by protein engineering. Nature. 1989:340:122-6.

5. Kuwajima K. The molten globule state as a clue for understanding the folding and cooperativity of globular-protein structure. Proteins. 1989;6:87-103.

6. Baldwin RL, Rose GD. Molten globules, entropy-driven conformational change and protein folding. Curr Opin Struct Biol. 2013:23:4-10.

7. Kim PS, Baldwin RL. Intermediates in the folding reactions of small proteins. Annu Rev Biochem. 1990;59:631-60.

8. Baldwin AJ, Kay LE. NMR spectroscopy brings invisible protein states into focus. Nat Methods. 2009;5:808-14.

9. Kim YE, Hipp MS, Bracher A, Hayer-Hartl M, Ulrich HF. Molecular chaperone functions in protein folding and proteostasis. Annu Rev Biochem. 2013;82:323-55.

10. Hartl FU, Bracher A, Hayer-Hartl M. Molecular chaperones in protein folding and proteostasis. Nature. 2011;475:324-32.

11. Freedberg DI, Selenko P. Live cell NMR. Annu Rev Biophys. 2014:43:171-92.

12. Thommen M, Holtkamp W, Rodnina MV. Co-translational protein folding: progress and methods. Curr Opin Struct Biol. 2017:42:83-9.

13. Nilsson OB, Hedman R, Marino J, Wickles S, Bischoff L, Johansson M, et al. Cotranslational protein folding inside the ribosome exit tunnel. Cell Rep. 2015;12:1533-40.

14. Holtkamp W, Kokic G, Jäger M, Mittelstaet J, Komar AA, Rodnina MV. Cotranslational protein folding on the ribosome monitored in real time. Science. 2015;350:1104-7.

15. Schlebach JP, Sanders CR. The safety dance: biophysics of membrane protein folding and misfolding in a cellular context. Q Rev Biophys. 2015;48:1-34.

16. Fleming KG. Energetics of membrane protein folding. Annu Rev Biophys. 2014:43:233-55.

17. Booth PJ, Curnow P. Folding scene investigation: membrane proteins. Curr Opin Struct Biol. 2009;19:8-13.

18. Stanley AM, Fleming KG. The process of folding proteins into membranes: challenges and progress. Arch Biochem Biophys. 2008;469:46-66.

19. Bowie JU. Solving the membrane protein folding problem. Nature. 2005:438:581-9.

20. Booth PJ, Templer RH, Meijberg W, Allen SJ, Curran AR, Lorch M. In vitro studies of membrane protein folding. Crit Rev Biochem Mol Biol. 2001:36:501-603.

21. White SH, Wimley WC. Membrane protein folding and stability: physical principles. Annu Rev Biophys Biomol Struct. 1999:28:319-65.

22. Pogozheva ID, Mosberg HI, Lomize AL. Life at the border: adaptation of proteins to anisotropic membrane environment. Protein Sci. 2014;23: 1165-96.

23. Kennedy SJ. Structures of membrane proteins. J Membr Biol. 1978:42:265-79.

24. Wimley WC, White SH. Experimentally determined hydrophobicity scale for proteins at membrane interfaces. Nat Struct Mol Biol. 1996;3:842-8.

25. Engelman DM, Steitz TA, Goldman A. Identifying nonpolar transbilayer helices in amino acid sequences of membrane proteins. Annu Rev Biophys Biophys Chem. 1986;15:321-53.

26. Kleffel B, Garavito RM, Baumeister W, Rosenbusch JP. Secondary structure of a channel-forming protein: porin from E. coli outer membranes. EMBO J. 1985;4:1589-92.

27. Popot JL, Engelman DM. Membrane protein folding and oligomerization: the two-stage model. Biochemistry. 1990;29:4031-7.

28. Hagan $\mathrm{CL}$, Silhavy TJ, Kahne D. $\beta$-Barrel membrane protein assembly by the Bam complex. Annu Rev Biochem. 2011;80:189-210.

29. Dornmair K, Kiefer H, Jähnig F. Refolding of an integral membrane protein. OmpA of Escherichia coli. J Biol Chem. 1990;265:18907-11.

30. Surrey $T$, Jähnig $F$. Refolding and oriented insertion of a membrane protein into a lipid bilayer. Proc Natl Acad Sci U S A. 1992:89:7457-61.

31. Surrey T, Schmid A, Jähnig F. Folding and membrane insertion of the trimeric beta-barrel protein OmpF. Biochemistry. 1996:35:2283-8.

32. Huysmans GHM, Radford SE, Brockwell DJ, Baldwin SA. The N-terminal helix is a post-assembly clamp in the bacterial outer membrane protein PagP. J Mol Biol. 2007;373:529-40. 
33. Burgess NK, Dao TP, Stanley AM. Fleming KG $\beta$-barrel proteins that reside in the Escherichia coli outer membrane in vivo demonstrate varied folding behavior in vitro. J Biol Chem. 2008;283:26748-58.

34. Anfinsen CB. Principles that govern the folding of protein chains. Science. 1973;181:223-30.

35. Fairman JW, Noinaj N, Buchanan SK. The structural biology of $\beta$-barrel membrane proteins: a summary of recent reports. Curr Opin Struct Biol. 2011;21:523-31.

36. Bos MP, Robert $\mathrm{V}$, Tommassen J. Biogenesis of the gram-negative bacterial outer membrane. Annu Rev Microbiol. 2007;61:191-214.

37. Dong H, Xiang Q, Gu Y, Wang Z, Paterson NG, Stansfeld PJ, et al. Structural basis for outer membrane lipopolysaccharide insertion. Nature. 2014;511:52-6.

38. Cao B, Zhao Y, Kou Y, Ni D, Zhang XC, Huang Y. Structure of the nonameric bacterial amyloid secretion channel. Proc Natl Acad Sci U S A 2014;111:E5439-44.

39. Barnhart MM, Chapman MR. Curli biogenesis and function. Annu Rev Microbiol. 2006;60:131-47.

40. Yan Z, Yin M, Xu D, Zhu Y, Li X. Structural insights into the secretin translocation channel in the type II secretion system. Nat Struct Mol Biol. 2017:24:177-83

41. Costa TRD, Felisberto-Rodrigues C, Meir A, Prevost MS, Redzej A, Trokter M, et al. Secretion systems in Gram-negative bacteria: structural and mechanistic insights. Nat Rev Micro. 2015;13:343-59.

42. de Leij L, Witholt B. Structural heterogeneity of the cytoplasmic and outer membranes of Escherichia coli. Biochim Biophys Acta Biomembr 1977;471:92-104.

43. Jarosławski S, Duquesne K, Sturgis JN, Scheuring S. High-resolution architecture of the outer membrane of the Gram-negative bacteria Roseobacter denitrificans. Mol Microbiol. 2009;74:1211-22.

44. Koebnik R. Membrane assembly of the Escherichia coli outer membrane protein OmpA: exploring sequence constraints on transmembrane betastrands. J Mol Biol. 1999;285:1801-10.

45. Lin $M$, Gessmann D, Naveed H, Liang J. Outer membrane protein folding and topology from a computational transfer free energy scale. J Am Chem Soc. 2016;138:2592-601.

46. Dill KA. Dominant forces in protein folding. Biochemistry. 1990;29:7133-55.

47. Nicholls A, Sharp KA, Honig B. Protein folding and association: insights from the interfacial and thermodynamic properties of hydrocarbons. Proteins. 1991;11:281-96.

48. Peterson $\mathrm{JH}$, Plummer AM, Fleming KG, Bernstein HD. Selective pressure for rapid membrane integration constrains the sequence of bacterial outer membrane proteins. Mol Microbiol. 2017;106(5):777-92.

49. Stapleton JA, Whitehead TA, Nanda V. Computational redesign of the lipid facing surface of the outer membrane protein OmpA. Proc Natl Acad Sci U S A. 2015;112:9632-7.

50. Hong H, Tamm LK. Elastic coupling of integral membrane protein stability to lipid bilayer forces. Proc Natl Acad Sci U S A. 2004;101:4065-70.

51. Hong H, Szabo G, Tamm LK. Electrostatic couplings in OmpA ion-channel gating suggest a mechanism for pore opening. Nat Chem Biol. 2006;2:627-35.

52. Hong H, Park S, Flores Jiménez RH, Rinehart D, Tamm LK. Role of aromatic side chains in the folding and thermodynamic stability of integral membrane proteins. J Am Chem Soc. 2007;129:8320-7.

53. Andersen $\mathrm{KK}$, Wang $\mathrm{H}$, Otzen DE. A kinetic analysis of the folding and unfolding of OmpA in urea and guanidinium chloride: single and parallel pathways. Biochemistry. 2012;51:8371-83.

54. Kleinschmidt JRH, Popot JL. Folding and stability of integral membrane proteins in amphipols. Arch Biochem Biophys. 2014;564:327-43.

55. Huysmans GHM, Baldwin SA, Brockwell DJ, Radford SE. The transition state for folding of an outer membrane protein. Proc Natl Acad Sci U S A. 2010;107:4099-104.

56. Moon CP, Zaccai NR, Fleming PJ, Gessmann D, Fleming KG. Membrane protein thermodynamic stability may serve as the energy sink for sorting in the periplasm. Proc Natl Acad Sci U S A. 2013;110:4285-90.

57. Iyer BR, Zadafiya P, Vetal PV, Mahalakshmi R. Energetics of side-chain partitioning of $\beta$-signal residues in unassisted folding of a transmembrane B-barrel protein. J Biol Chem. 2017;292:12351-65.

58. Moon CP, Kwon S, Fleming KG. Overcoming hysteresis to attain reversible equilibrium folding for outer membrane phospholipase a in phospholipid bilayers. J Mol Biol. 2011;413:484-94.
59. Inouye M, Yee M-L. Homogeneity of envelope proteins of Escherichia coli separated by gel electrophoresis in sodium dodecyl sulfate. J Bacteriol. 1973;113:304-12.

60. Schweizer M, Hindennach I, Garten W, Henning U. Major proteins of the Escherichia coli outer cell envelope membrane. Interaction of protein II with lipopolysaccharide. Eur J Biochem. 1978;82:211-7.

61. Nakamura K, Mizushima S. Effects of heating in dodecyl sulfate solution on the conformation and electrophoretic mobility of isolated major outer membrane proteins from Escherichia coli K-12. J Biochem. 1976;80:1411-22.

62. Moon CP, Fleming KG. Side-chain hydrophobicity scale derived from transmembrane protein folding into lipid bilayers. Proc Natl Acad Sci U S A. 2011:108:10174-7.

63. Qu J, Mayer C, Behrens S, Holst O, Kleinschmidt JH. The trimeric periplasmic chaperone Skp of Escherichia coli forms 1:1 complexes with outer membrane proteins via hydrophobic and electrostatic interactions. J Mol Biol. 2007:374:91-105

64. Wu S, Ge X, Lv Z, Zhi Z, Chang Z, Zhao XS. Interaction between bacterial outer membrane proteins and periplasmic quality control factors: a kinetic partitioning mechanism. Biochem J. 2011;438:505-11.

65. Schiffrin B, Calabrese AN, Higgins AJ, Humes JR, Ashcroft AE, Kalli AC, et al. Effects of periplasmic chaperones and membrane thickness on BamAcatalysed outer membrane protein folding. J Mol Biol. 2017. doi: 10.1016/j. jmb.2017.09.008.

66. Wülfing C, Plückthun A. Protein folding in the periplasm of Escherichia coli. Mol Microbiol. 1994:12:685-92.

67. Fleming KG. A combined kinetic push and thermodynamic pull as driving forces for outer membrane protein sorting and folding in bacteria. Philos Trans R Soc Lond B Biol Sci. 2015;370:20150026.

68. Gershenson A, Gierasch LM, Pastore A, Radford SE. Energy landscapes of functional proteins are inherently risky. Nat Rev Mol Cell Biol. 2014;10:884-91.

69. Pocanschi $\mathrm{CL}$, Apell H-J, Puntervoll P, Høgh B, Jensen HB, Welte W, et al. The Major outer membrane protein of Fusobacterium nucleatum (FomA) folds and inserts into lipid bilayers via parallel folding pathways. J Mol Biol. 2006;355:548-61.

70. Pocanschi $\mathrm{CL}$, Popot $J$, Kleinschmidt JH. Folding and stability of outer membrane protein $\mathrm{A}(\mathrm{OmpA})$ from Escherichia coli in an amphipathic polymer, amphipol A8-35. Eur Biophys J. 2013;42:103-18.

71. Shakhnovich BE, Deeds E, Delisi C, Shakhnovich E. Protein structure and evolutionary history determine sequence space topology. Genome Res. 2005;15:385-92.

72. Iyer BR, Mahalakshmi R. Residue-dependent thermodynamic cost and barrel plasticity balances activity in the PhoPQ-activated enzyme PagP of Salmonella typhimurium. Biochemistry. 2015;54:5712-22.

73. Cuesta-Seijo JA, Neale C, Khan MA, Moktar J, Tran CD, Bishop RE, et al. PagP crystallized from SDS/cosolvent reveals the route for phospholipid access to the hydrocarbon ruler. Struct Fold Des. 2010;18:1210-9.

74. van den Berg B. The FadL family: unusual transporters for unusual substrates. Curr Opin Struct Biol. 2005:15:401-7.

75. Hong H, Patel DR, Tamm LK, van den Berg B. The outer membrane protein OmpW forms an eight-stranded beta-barrel with a hydrophobic channel. J Biol Chem. 2006;281:7568-77

76. Noinaj N, Kuszak AJ, Gumbart JC, Lukacik P, Chang H, Easley NC, et al. Structural insight into the biogenesis of $\beta$-barrel membrane proteins. Nature. 2013;501:385-90.

77. Bakelar J, Buchanan SK, Noinaj N. The structure of the $\beta$-barrel assembly machinery complex. Science. 2016;351:180-6.

78. Gu Y, Li H, Dong H, Zeng Y, Zhang Z, Paterson NG, et al. Structural basis of outer membrane protein insertion by the BAM complex. Nature. 2016;531:64-9.

79. Iadanza MG, Higgins AJ, Schiffrin B, Calabrese AN, Brockwell DJ, Ashcroft AE, et al. Lateral opening in the intact $\beta$-barrel assembly machinery captured by cryo-EM. Nat Commun. 2016;7:12865.

80. Doerner PA, Sousa MC. Extreme dynamics in the BamA $\beta$-barrel seam Biochemistry. 2017:56:3142-9.

81. Killian JA, von Heijne G. How proteins adapt to a membrane-water interface. Trends Biochem Sci. 2000;25:429-34

82. Yau W-M, Wimley WC, Gawrisch K, White SH. The preference of tryptophan for membrane interfaces. Biochemistry. 1998;37:14713-8.

83. McDonald SK, Fleming KG. Aromatic side chain water-to-lipid transfer free energies show a depth dependence across the membrane normal. J Am Chem Soc. 2016;138:7946-50. 
84. Jackups Jr R, Liang J. Interstrand pairing patterns in $\beta$-barrel membrane proteins: the positive-outside rule, aromatic rescue, and strand registration prediction. J Mol Biol. 2005;354:979-93.

85. von Heijne G. Membrane protein structure prediction. Hydrophobicity analysis and the positive-inside rule. J Mol Biol. 1992;225:487-94.

86. Marx DC, Fleming KG. Influence of protein scaffold on side-chain transfer free energies. Biophys J. 2017;113:597-604.

87. Ferguson AD, Hofmann E, Coulton JW, Diederichs K, Welte W. Siderophoremediated iron transport: crystal structure of FhuA with bound lipopolysaccharide. Science. 1998;282:2215-20.

88. Kucharska I, Liang B, Ursini N, Tamm LK. Molecular interactions of lipopolysaccharide with an outer membrane protein from Pseudomonas aeruginosa probed by solution NMR. Biochemistry. 2016;55:5061-72.

89. Arunmanee W, Pathania M, Solovyova AS, Le Brun AP, Ridley H, Baslé A, et al. Gram-negative trimeric porins have specific LPS binding sites that are essential for porin biogenesis. Proc Natl Acad Sci U S A. 2016:113:E5034-43.

90. Lomize AL, Pogozheva ID, Lomize MA, Mosberg HI. Positioning of proteins in membranes: A computational approach. Protein Sci. 2006;15:1318-33.

91. Wu EL, Fleming PJ, Yeom MS, Widmalm G, Klauda JB, Fleming KG, et al. E. coli outer membrane and interactions with OmpLA. Biophys J. 2014;106:2493-502.

92. Merkel JS, Regan L. Aromatic rescue of glycine in $\beta$ sheets. Fold Des. 1998;3:449-56.

93. Michalik M, Orwick-Rydmark M, Habeck M, Alva V, Arnold T, Linke D. An evolutionarily conserved glycine-tyrosine motif forms a folding core in outer membrane proteins. PLoS One. 2017;12:e0182016-23.

94. Leyton DL, Johnson MD, Thapa R, Huysmans GHM, Dunstan RA, Celik N, et al. A mortise-tenon joint in the transmembrane domain modulates autotransporter assembly into bacterial outer membranes. Nat Commun. 2014:5:4239.

95. Frey L, Lakomek N-A, Riek R, Bibow S. Micelles, Bicelles, and Nanodiscs: Comparing the impact of membrane mimetics on membrane protein backbone dynamics. Angew Chem Int Ed Engl. 2017;56:380-3.

96. Bryngelson JD, Onuchic JN, Socci ND, Wolynes PG. Funnels, pathways, and the energy landscape of protein folding: a synthesis. Proteins. 1995;21:167-95.

97. Onuchic JN, Luthey-Schulten Z, Wolynes PG. Theory of protein folding: the energy landscape perspective. Annu Rev Phys Chem. 1997;48:545-600.

98. Wolynes PG. Evolution, energy landscapes and the paradoxes of protein folding. Biochimie. 2015;119:218-30.

99. Ferreiro DU, Komives EA, Wolynes PG. Frustration in biomolecules. Q Rev Biophys. 2014;47:285-363.

100. Popot JL. Folding membrane proteins in vitro: a table and some comments. Arch Biochem Biophys. 2014;564:314-26.

101. Kleinschmidt JH. Folding of $\beta$-barrel membrane proteins in lipid bilayers Unassisted and assisted folding and insertion. Biochim Biophys Acta Biomembr. 2015;1848:1927-43.

102. Chaturvedi D, Mahalakshmi R. Transmembrane $\beta$-barrels: evolution, folding and energetics. Biochim Biophys Acta. 2017;1859:2467-82.

103. Kleinschmidt JH, Tamm LK. Folding intermediates of a beta-barrel membrane protein. Kinetic evidence for a multi-step membrane insertion mechanism. Biochemistry. 1996;35:12993-3000.

104. Rodionova NA, Tatulian SA, Surrey T, Jaehnig F. Characterization of two membrane-bound forms of OmpA. Biochemistry. 1995;34:1921-9.

105. Patel GJ, Behrens-Kneip S, Holst O, Kleinschmidt JH. The periplasmic chaperone Skp facilitates targeting, insertion, and folding of OmpA into lipid membranes with a negative membrane surface potential. Biochemistry. 2009;48:10235-45.

106. Kleinschmidt $\mathrm{JH}$. Folding kinetics of the outer membrane proteins OmpA and FomA into phospholipid bilayers. Chem Phys Lipids. 2006:141:30-47.

107. Huysmans GHM, Radford SE, Baldwin SA, Brockwell DJ. Malleability of the folding mechanism of the outer membrane protein PagP: parallel pathways and the effect of membrane elasticity. J Mol Biol. 2012;416: 453-64.

108. Danoff EJ, Fleming KG. Novel kinetic intermediates populated along the folding pathway of the transmembrane $\beta$-barrel OmpA. Biochemistry. 2017:56:47-60.

109. Krishna MMG, Englander SW. A unified mechanism for protein folding: Predetermined pathways with optional errors. Protein Sci. 2007;16:449-64.

110. Wzorek JS, Lee J, Tomasek D, Hagan CL, Kahne DE. Membrane integration of an essential $\beta$-barrel protein prerequires burial of an extracellular loop. Proc Natl Acad Sci U S A. 2017;114:2598-603.
111. Kleinschmidt JH, den Blaauwen T, Driessen AJ, Tamm LK. Outer membrane protein A of Escherichia coli inserts and folds into lipid bilayers by a concerted mechanism. Biochemistry. 1999;38:5006-16.

112. Kleinschmidt JH, Tamm LK. Secondary and tertiary structure formation of the $\beta$-barrel membrane protein OmpA is synchronized and depends on membrane thickness. J Mol Biol. 2002;324:319-30.

113. Raschle T, Rios Flores P, Opitz C, Müller DJ, Hiller S. Monitoring backbone hydrogen-bond formation in $\beta$-barrel membrane protein folding. Angew Chem. 2016;128:6056-9.

114. Tan AE, Burgess NK, DeAndrade DS, Marold JD, Fleming KG. Self-association of unfolded outer membrane proteins. Macromol Biosci. 2010;10:763-7.

115. Wang H, Andersen KK, Vad BS, Otzen DE. OmpA can form folded and unfolded oligomers. Biochim Biophys Acta, Proteins Proteomics. 2013;1834:127-36.

116. West MW, Wang W, Patterson J, Mancias JD, Beasley JR, Hecht MH. De novo amyloid proteins from designed combinatorial libraries. Proc Natl Acad Sci U S A. 1999;96:11211-6.

117. Stroobants K, Kumita JR, Harris NJ, Chirgadze DY, Dobson CM, Booth PJ, et al. Amyloid-like fibrils from an a-helical transmembrane protein. Biochemistry. 2017:56:3225-33.

118. Danoff EJ, Fleming KG. Aqueous, unfolded OmpA forms amyloid-like fibrils upon self-association. PLoS One. 2015;10:e0132301-10.

119. Knowles TPJ, Vendruscolo M, Dobson CM. The amyloid state and its association with protein misfolding diseases. Nat Rev Mol Cell Biol. 2014;15:384-96.

120. Tipping KW, van Oosten-Hawle P, Hewitt EW, Radford SE. Amyloid fibres: inert end-stage aggregates or key players in disease? Trends Biochem Sci. 2015:40:719-27.

121. Otzen DE, Andersen KK. Folding of outer membrane proteins. Arch Biochem Biophys. 2013;531:34-43.

122. Marsh D, Shanmugavadivu B, Kleinschmidt JH. Membrane elastic fluctuations and the insertion and tilt of beta-barrel proteins. Biophys J. 2006:91:227-32.

123. Pocanschi CL, Patel GJ, Marsh D, Kleinschmidt JH. Curvature elasticity and refolding of OmpA in large unilamellar vesicles. Biophys J. 2006;91:L75-7.

124. Maurya SR, Chaturvedi D, Mahalakshmi R. Modulating lipid dynamics and membrane fluidity to drive rapid folding of a transmembrane barrel. Sci Rep. 2013;3:1-6.

125. McMorran LM, Bartlett Al, Huysmans GHM, Radford SE, Brockwell DJ. Dissecting the effects of periplasmic chaperones on the in vitro folding of the outer membrane protein PagP. J Mol Biol. 2013:425:3178-91.

126. Patel GJ, Kleinschmidt JH. The lipid bilayer-inserted membrane protein BamA of Escherichia coli facilitates insertion and folding of outer membrane protein A from its complex with Skp. Biochemistry. 2013;52:3974-86.

127. Gessmann D, Chung YH, Danoff EJ, Plummer AM, Sandlin CW, Zaccai NR, et al. Outer membrane $\beta$-barrel protein folding is physically controlled by periplasmic lipid head groups and BamA. Proc Natl Acad Sci U S A. 2014;111:5878-83.

128. Hagan CL, Kim S, Kahne D. Reconstitution of outer membrane protein assembly from purified components. Science. 2010;328:890-2.

129. Hagan CL, Kahne D. The reconstituted Escherichia coli Bam complex catalyzes multiple rounds of $\beta$-barrel assembly. Biochemistry. 2011:50:7444-6.

130. Hagan CL, Westwood DB, Kahne D. Bam lipoproteins assemble BamA in vitro. Biochemistry. 2013;52:6108-13.

131. Roman-Hernandez G, Peterson JH, Bernstein HD. Reconstitution of bacterial autotransporter assembly using purified components. elife. 2014;3:711-48.

132. Plummer AM, Fleming KG. BamA alone accelerates outer membrane protein folding in vitro through a catalytic mechanism. Biochemistry. 2015;54:6009-11.

133. Webb CT, Heinz E, Lithgow T. Evolution of the $\beta$-barrel assembly machinery. Trends Microbiol. 2012;20:612-20.

134. Behrens-Kneip S. The role of SurA factor in outer membrane protein transport and virulence. Int J Med Microbiol. 2010;300:421-8.

135. Burmann BM, Holdbrook DA, Callon M, Bond PJ, Hiller S. Revisiting the interaction between the chaperone Skp and lipopolysaccharide. Biophys J. 2015:108:1516-26

136. Ellis RJ, Hartl FU. Principles of protein folding in the cellular environment. Curr Opin Struct Biol. 1999:9:102-10.

137. Hipp MS, Park SH, Hartl FU. Proteostasis impairment in protein-misfolding and-aggregation diseases. Trends Cell Biol. 2014;24:506-14.

138. Goemans C, Denoncin K, Collet J-F. Folding mechanisms of periplasmic proteins. Biochim Biophys Acta, Mol Cell Res. 2014;1843:1517-28.

139. De Geyter J, Tsirigotaki A, Orfanoudaki G, Zorzini V, Economou A, Karamanou S. Protein folding in the cell envelope of Escherichia coli. Nat Microbiol. 2016;1:16107. 
140. McMorran LM, Brockwell DJ, Radford SE. Mechanistic studies of the biogenesis and folding of outer membrane proteins in vitro and in vivo: what have we learned to date? Arch Biochem Biophys. 2014;564:265-80

141. Lyu Z-X, Shao Q, Gao YQ, Zhao XS. Direct observation of the uptake of outer membrane proteins by the periplasmic chaperone Skp. PLoS One. 2012;7:e46068-13.

142. Zaccai NR, Sandlin CW, Hoopes JT, Curtis JE, Fleming PJ, Fleming KG, et al. Deuterium labeling together with contrast variation small-angle neutron scattering suggests how skp captures and releases unfolded outer membrane proteins. Methods Enzymol. 2016;566:159-210.

143. Schiffrin B, Calabrese AN, Devine PWA, Harris SA, Ashcroft AE, Brockwell DJ, et al. Skp is a multivalent chaperone of outer-membrane proteins. Nat Struct Mol Biol. 2016;23:786-93.

144. Holdbrook DA, Burmann BM, Huber RG, Petoukhov MV, Svergun DI, Hiller S, et al. A spring-loaded mechanism governs the clamp-like dynamics of the Skp chaperone. Structure. 2017;25:1079-1088.e3.

145. Costello SM, Plummer AM, Fleming PJ, Fleming KG. Dynamic periplasmic chaperone reservoir facilitates biogenesis of outer membrane proteins. Proc Natl Acad Sci U S A. 2016;113:E4794-800.

146. Burmann BM, Wang C, Hiller S. Conformation and dynamics of the periplasmic membrane-protein-chaperone complexes OmpX-Skp and tOmpA-Skp. Nat Struct Mol Biol. 2013;20:1265-72.

147. Callon M, Burmann BM, Hiller S. Structural mapping of a chaperone-substrate interaction surface. Angew Chem Int Ed Engl. 2014;53:5069-72.

148. Bitto E, McKay DB. Crystallographic structure of SurA, a molecular chaperone that facilitates folding of outer membrane porins. Struct Fold Des. 2002;10:1489-98.

149. Saio T, Guan X, Rossi P, Economou A, Kalodimos CG. Structural basis for protein antiaggregation activity of the trigger factor chaperone. Science. 2014:344:1250494-4.

150. Huang C, Rossi P, Saio T, Kalodimos CG. Structural basis for the antifolding activity of a molecular chaperone. Nature. 2016;537:202-6.

151. Thoma J, Burmann BM, Hiller S, Müller DJ. Impact of holdase chaperones Skp and SurA on the folding of $\beta$-barrel outer-membrane proteins. Nat Struct Mol Biol. 2015;22:795-802.

152. Bitto E, McKay DB. The periplasmic molecular chaperone protein SurA binds a peptide motif that is characteristic of integral outer membrane proteins. J Biol Chem. 2003;278:49316-22.

153. Hennecke G, Nolte J, Volkmer-Engert R, Schneider-Mergener J, Behrens S. The periplasmic chaperone SurA exploits two features characteristic of integral outer membrane proteins for selective substrate recognition. J Biol Chem. 2005;280:23540-8.

154. Jarchow S, Lück C, Görg A, Skerra A. Identification of potential substrate proteins for the periplasmic Escherichia coli chaperone Skp. Proteom. 2008:8:4987-94

155. Vertommen D, Ruiz N, Leverrier P, Silhavy TJ, Collet J-F. Characterization of the role of the Escherichia coli periplasmic chaperone SurA using differential proteomics. Proteom. 2009:9:2432-43.

156. Behrens S, Maier R, De Cock H, Schmid FX, Gross CA. The SurA periplasmic PPlase lacking its parvulin domains functions in vivo and has chaperone activity. EMBO J. 2001;20:285-94.

157. Walton TA, Sandoval CM, Fowler CA, Pardi A, Sousa MC. The cavity-chaperone Skp protects its substrate from aggregation but allows independent folding of substrate domains. Proc Natl Acad Sci U S A. 2009;106:1772-7.

158. Ha SC, Pereira JH, Jeong JH, Huh JH, Kim S-H. Purification of human transcription factors Nanog and Sox2, each in complex with Skp, an Escherichia coli periplasmic chaperone. Protein Expr Purif. 2009;67:164-8.

159. Entzminger KC, Chang C, Myhre RO, McCallum KC, Maynard JA. The Skp chaperone helps fold soluble proteins in vitroby inhibiting aggregation. Biochemistry. 2012;51:4822-34.

160. He L, Sharpe T, Mazur A, Hiller S. A molecular mechanism of chaperone-client recognition. Sci Adv. 2016;2:e1601625-5.

161. Tafer H, Hiller S, Hilty C, Fernández C, Wüthrich K. Nonrandom structure in the urea-unfolded Escherichia coli outer membrane protein X (OmpX). Biochemistry. 2004:43:860-9.

162. Hiller S, Wider G, Imbach LL, Wüthrich K. Interactions with hydrophobic clusters in the urea-unfolded membrane protein OmpX. Angew Chem Int Ed. 2008;47:977-81.

163. Krainer G, Gracia P, Frotscher E, Hartmann A, Gröger P, Keller S, et al. Slow interconversion in a heterogeneous unfolded-state ensemble of outermembrane phospholipase A. Biophys J. 2017;113:1280-9.
164. Danoff EJ, Fleming KG. The soluble, periplasmic domain of OmpA folds as an independent unit and displays chaperone activity by reducing the selfassociation propensity of the unfolded OmpA transmembrane $\beta$-barrel. Biophys Chem. 2011;159:194-204.

165. Noinaj N, Guillier M, Barnard TJ, Buchanan SK. TonB-dependent transporters: regulation, structure, and function. Annu Rev Microbiol. 2010;64:43-60.

166. Lee J, Xue M, Wzorek JS, Wu T, Grabowicz M, Gronenberg LS, et al. Characterization of a stalled complex on the $\beta$-barrel assembly machine. Proc Natl Acad Sci U S A. 2016;113:8717-22.

167. Duguay AR, Silhavy TJ. Quality control in the bacterial periplasm. Biochim Biophys Acta, Mol Cell Res. 2004;1694:121-34.

168. Ruiz N, Silhavy TJ. Sensing external stress: watchdogs of the Escherichia coli cell envelope. Curr Opin Microbiol. 2005:8:122-6.

169. Raivio TL. Everything old is new again: an update on current research on the Cpx envelope stress response. Biochim Biophys Acta. 2014;1843:1529-41.

170. Mecsas J, Rouviere PE, Erickson JW. The activity of sigma E, an Escherichia coli heat-inducible sigma-factor, is modulated by expression of outer membrane proteins. Genes Dev. 1993;7:2618-28.

171. Narita S-I, Masui C, Suzuki T, Dohmae N, Akiyama Y. Protease homolog BepA (YfgC) promotes assembly and degradation of $\beta$-barrel membrane proteins in Escherichia coli. Proc Natl Acad Sci U S A. 2013;110:E3612-21.

172. Soltes GR, Martin NR, Park E, Sutterlin HA, Silhavy TJ. Distinctive roles for periplasmic proteases in the maintenance of essential outer membrane protein assembly. J Bacteriol. 2017. doi: 10.1128/JB.00418-17.

173. Rassam P, Copeland NA, Birkholz O, Tóth C, Chavent M, Duncan AL, et al. Supramolecular assemblies underpin turnover of outer membrane proteins in bacteria. Nature. 2015:523:333-6.

174. Kleanthous C, Rassam P, Baumann CG. Protein-protein interactions and the spatiotemporal dynamics of bacterial outer membrane proteins. Curr Opin Struct Biol. 2015;35:109-15

175. Powers ET, Powers DL, Gierasch LM. FoldEco: A model for proteostasis in E. coli. Cell Rep. 2012;1:265-76.

176. Kim KH, Aulakh S, Paetzel M. The bacterial outer membrane $\beta$-barrel assembly machinery. Protein Sci. 2012;21:751-68.

177. Ricci DP, Silhavy TJ. The Bam machine: a molecular cooper. Biochim Biophys Acta Biomembr. 2012;1818:1067-84.

178. Rollauer SE, Sooreshjani MA, Noinaj N, Buchanan SK. Outer membrane protein biogenesis in Gram-negative bacteria. Philos Trans R Soc Lond B Biol Sci. 2015;370:20150023.

179. Plummer AM, Fleming KG. From chaperones to the membrane with a BAM! Trends Biochem Sci. 2016;41:872-82.

180. Botos I, Noinaj N, Buchanan SK. Insertion of proteins and lipopolysaccharide into the bacterial outer membrane. Phil Trans R Soc B. 2017;372:20160224-9.

181. Noinaj N, Gumbart JC, Buchanan SK. The $\beta$-barrel assembly machinery in motion. Nat Rev Micro. 2017;15:197-204.

182. Konovalova A, Kahne DE, Silhavy TJ. Outer membrane biogenesis. Annu Rev Microbiol. 2017;71:539-56.

183. Knowles TJ, Scott-Tucker A, Overduin M, Henderson IR. Membrane protein architects: the role of the BAM complex in outer membrane protein assembly. Nat Rev Micro. 2009;7:206-14.

184. Selkrig J, Leyton DL, Webb CT, Lithgow T. Assembly of $\beta$-barrel proteins into bacterial outer membranes. Biochim Biophys Acta. 2014;1843:1542-50.

185. Voulhoux R. Role of a highly conserved bacterial protein in outer membrane protein assembly. Science. 2003:299:262-5.

186. Wu T, Malinverni J, Ruiz N, Kim S, Silhavy TJ, Kahne D. Identification of a multicomponent complex required for outer membrane biogenesis in Escherichia coli. Cell. 2005;121:235-45.

187. Malinverni JC, Werner J, Kim S, Sklar JG, Kahne D, Misra R, et al. YfiO stabilizes the YaeT complex and is essential for outer membrane protein assembly in Escherichia coli. Mol Microbiol. 2006;61:151-64.

188. Sklar JG, Wu T, Kahne D, Silhavy TJ. Defining the roles of the periplasmic chaperones SurA, Skp, and DegP in Escherichia coli. Genes Dev. 2007:21:2473-84

189. Bennion D, Charlson ES, Coon E, Misra R. Dissection of $\beta$-barrel outer membrane protein assembly pathways through characterizing BamA POTRA 1 mutants of Escherichia coli. Mol Microbiol. 2010;77:1153-71.

190. Lugtenberg EJ, Peters R. Distribution of lipids in cytoplasmic and outer membranes of Escherichia coli K12. Biochim Biophys Acta. 1976;441:38-47.

191. De Cock H, Struyvé M, Kleerebezem M, van der Krift T, Tommassen J. Role of the carboxy-terminal phenylalanine in the biogenesis of outer 
membrane protein PhoE of Escherichia coli K-12. J Mol Biol. 1997:269:473-8.

192. Struyvé M, Moons M, Tommassen J. Carboxy-terminal phenylalanine is essential for the correct assembly of a bacterial outer membrane protein. J Mol Biol. 1991;218:141-8.

193. Hagan CL, Wzorek JS, Kahne D. Inhibition of the $\beta$-barrel assembly machine by a peptide that binds BamD. Proc Natl Acad Sci U S A. 2015;112:2011-6.

194. Albrecht R, Zeth K. Structural basis of outer membrane protein biogenesis in bacteria. J Biol Chem. 2011;286:27792-803.

195. Robert V, Volokhina EB, Senf F, Bos MP, Van Gelder P, Tommassen J. Assembly factor Omp85 recognizes its outer membrane protein substrates by a speciesspecific C-terminal motif. PLoS Biol. 2006;4:e377.

196. Danoff EJ, Fleming KG. Membrane defects accelerate outer membrane $\beta$ barrel protein folding. Biochemistry. 2015;54:97-9.

197. Noinaj N, Kuszak AJ, Balusek C, Gumbart JC, Buchanan SK. Lateral opening and exit pore formation are required for BamA function. Structure. 2014;22:1055-62

198. Gruss F, Zähringer F, Jakob RP, Burmann BM, Hiller S, Maier T. The structural basis of autotransporter translocation by TamA. Nat Struct Mol Biol. 2013;20:1318-20.

199. Han L, Zheng J, Wang Y, Yang X, Liu Y, Sun C, et al. Structure of the BAM complex and its implications for biogenesis of outer-membrane proteins. Nat Struct Mol Biol. 2016;23:192-6.

200. Mahoney TF, Ricci DP, Silhavy TJ. Classifying $\beta$-barrel assembly substrates by manipulating essential Bam complex members. J Bacteriol. 2016;198:1984-92.

201. Eichner T, Radford SE. A diversity of assembly mechanisms of a generic amyloid fold. Mol Cell. 2011;43:8-18.

202. Kleinschmidt JH, Bulieris PV, Qu J, Dogterom M, den Blaauwen T. Association of neighboring $\beta$-strands of outer membrane protein $A$ in lipid bilayers revealed by site-directed fluorescence quenching. J Mol Biol. 2011:407:316-32.

203. Schulz GE. $\beta$-barrel membrane proteins. Curr Opin Struct Biol. 2000;10:443-7.

204. Sapra KT, Damaghi M, Köster S, Yildiz Ö, Kühlbrandt W, Müller DJ. One $\beta$ hairpin after the other: exploring mechanical unfolding pathways of the transmembrane $\beta$-barrel protein OmpG. Angew Chem Int Ed. 2009;48:8306-8.

205. Thoma J, Bosshart $P$, Pfreundschuh M, Müller DJ. Out but not in: the large transmembrane $\beta$-barrel protein FhuA unfolds but cannot refold via $\beta$ hairpins. Structure. 2012;20:2185-90.

206. Ricci DP, Hagan CL, Kahne D, Silhavy TJ. Activation of the Escherichia coli $\beta$-barrel assembly machine (Bam) is required for essential components to interact properly with substrate. Proc Natl Acad Sci U S A. 2012;109:3487-91.

207. McCabe AL, Ricci D, Adetunji M, Silhavy TJ. Conformational changes that coordinate the activity of BamA and BamD allowing $\beta$-barrel assembly. J. Bacteriol. 2017. doi: 10.1128/JB.00373-17.

208. Warner LR, Gatzeva-Topalova PZ, Doerner PA, Pardi A, Sousa MC. Flexibility in the periplasmic domain of BamA is important for function. Structure. 2017;25:94-106.

209. Kim S, Malinverni JC, Sliz P, Silhavy TJ, Harrison SC, Kahne D. Structure and function of an essential component of the outer membrane protein assembly machine. Science. 2007;317:961-4

210. Gatzeva-Topalova PZ, Walton TA, Sousa MC. Crystal Structure of YaeT: conformational flexibility and substrate recognition. Struct Fold Des. 2008;16:1873-81.

211. Rigel NW, Ricci DP, Silhavy TJ. Conformation-specific labeling of BamA and suppressor analysis suggest a cyclic mechanism for $\beta$-barrel assembly in Escherichia coli. Proc Natl Acad Sci U S A. 2013;110:5151-6.

212. Rigel NW, Schwalm J, Ricci DP, Silhavy TJ. BamE modulates the Escherichia coli beta-barrel assembly machine component BamA. J Bacteriol. 2012;194:1002-8

213. Bernstein HD. Looks can be deceiving: recent insights into the mechanism of protein secretion by the autotransporter pathway. Mol Microbiol. 2015;97:205-15.

214. leva R, Bernstein HD. Interaction of an autotransporter passenger domain with BamA during its translocation across the bacterial outer membrane. Proc Natl Acad Sci U S A. 2009;106:19120-5.

215. leva R, Tian P, Peterson JH, Bernstein HD. Sequential and spatially restricted interactions of assembly factors with an autotransporter $\beta$ domain. Proc Natl Acad Sci U S A. 2011;108:E383-91.

216. Rossiter AE, Leyton DL, Tveen-Jensen K, Browning DF, Sevastsyanovich $Y$, Knowles TJ, et al. The essential $\beta$-barrel assembly machinery complex components BamD and BamA are required for autotransporter biogenesis. J Bacteriol. 2011;193:4250-3.
217. Grijpstra J, Arenas J, Rutten L, Tommassen J. Autotransporter secretion: varying on a theme. Res Microbiol. 2013;164:562-82.

218. Albenne C, leva R. Job contenders: roles of the $\beta$-barrel assembly machinery and the translocation and assembly module in autotransporter secretion. Mol Microbiol. 2017;106:505-17.

219. Bamert RS, Lundquist K, Hwang H, Webb CT, Shiota T, Stubenrauch CJ, et al. Structural basis for substrate selection by the translocation and assembly module of the $\beta$-barrel assembly machinery. Mol Microbiol. 2017;106(1):142-56.

220. Geibel S, Procko E, Hultgren SJ, Baker D, Waksman G. Structural and energetic basis of folded-protein transport by the FimD usher. Nature. 2014;496:243-6.

221. Horne JE, Radford SE. A growing toolbox of techniques for studying $\beta$ barrel outer membrane protein folding and biogenesis. Biochem Soc Trans. 2016;44:802-9.

222. Hagn F, Etzkorn M, Raschle T, Wagner G. Optimized phospholipid bilayer nanodiscs facilitate high-resolution structure determination of membrane proteins. J Am Chem Soc. 2013;135:1919-25.

223. Pautsch A, Schulz GE. High-resolution structure of the OmpA membrane domain. J Mol Biol. 2000;298:273-82.

224. Vandeputte-Rutten L, Kramer RA, Kroon J, Dekker N, Egmond MR, Gros P. Crystal structure of the outer membrane protease OmpT from Escherichia coli suggests a novel catalytic site. EMBO J. 2001;20:5033-9.

225. Barnard TJ, Dautin N, Lukacik P, Bernstein HD, Buchanan SK. Autotransporter structure reveals intra-barrel cleavage followed by conformational changes. Nat Struct Mol Biol. 2007;14:1214-20.

226. Snijder HJ, Ubarretxena-Belandia I, Blaauw M, Kalk KH, Verheij HM, Egmond $M R$, et al. Structural evidence for dimerization-regulated activation of an integral membrane phospholipase. Nature. 1999;401:717-21.

227. Yildiz Ö, Vinothkumar KR, Goswami P, Kühlbrandt W. Structure of the monomeric outer-membrane porin OmpG in the open and closed conformation. EMBO J. 2006;25:3702-13.

228. van den Berg B, Black PN, Clemons WM, Rapoport TA. Crystal structure of the long-chain fatty acid transporter FadL. Science. 2004;304:1506-9.

229. Cowan SW, Garavito RM, Jansonius JN, Jenkins JA, Karlsson R, König N, et al. The structure of OmpF porin in a tetragonal crystal form. Struct Fold Des. 1995;3:1041-50.

230. Schirmer T, Keller TA, Wang YF, Rosenbusch JP. Structural basis for sugar translocation through maltoporin channels at $3.1 \mathrm{~A}$ resolution. Science. 1995;267:512-4.

231. Locher KP, Rees B, Koebnik R, Mitschler A, Moulinier L, Rosenbusch JP, et al. Transmembrane signaling across the ligand-gated FhuA receptor: crystal structures of free and ferrichrome-bound states reveal allosteric changes. Cell. 1998;95:771-8.

232. Phan G, Remaut H, Wang T, Allen WJ, Pirker KF, Lebedev A, et al. Crystal structure of the FimD usher bound to its cognate FimC-FimH substrate. Nature. 2011;474:49-53.

233. Qiao S, Luo Q, Zhao Y, Zhang XC, Huang Y. Structural basis for lipopolysaccharide insertion in the bacterial outer membrane. Nature. 2014:511:108-11.

234. O'Neil PK, Rollauer SE, Noinaj N, Buchanan SK. Fitting the pieces of the $\beta$ barrel assembly machinery complex. Biochemistry. 2015;54:6303-11.

235. Ferguson AD, Ködding J, Walker G, Bös C, Coulton JW, Diederichs K, et al. Active transport of an antibiotic rifamycin derivative by the outer-membrane protein FhuA. Struct Fold Des. 2001;9:707-16.

236. Baker NA, Sept D, Joseph S, Holst MJ, McCammon JA. Electrostatics of nanosystems: application to microtubules and the ribosome. Proc Natl Acad Sci U S A. 2001;98:10037-41.

237. Hwang PM, Choy W-Y, Lo El, Chen L, Forman-Kay JD, Raetz CRH, et al. Solution structure and dynamics of the outer membrane enzyme PagP by NMR. Proc Natl Acad Sci U S A. 2002;99:13560-5.

238. Fiser A, Do RK, Sali A. Modeling of loops in protein structures. Protein Sci. 2000;9:1753-73.

239. Bischoff $L$, Wickles S, Berninghausen O, van der Sluis EO, Beckmann R. Visualization of a polytopic membrane protein during SecY-mediated membrane insertion. Nat Commun. 2014;5:4103.

240. Walton TA, Sousa MC. Crystal Structure of Skp, a Prefoldin-like chaperone that protects soluble and membrane proteins from aggregation. Mol Cell. 2004;15:367-74.

241. Schrödinger, LLC. The PyMOL Molecular Graphics System, Version 1.8. 2015. https://pymol.org.

242. Walsh NP, Alba BM, Bose B, Gross CA, Sauer RT. OMP peptide signals initiate the envelope-stress response by activating DegS protease via relief of inhibition mediated by its PDZ domain. Cell. 2003;113:61-71. 
243. Merdanovic M, Clausen T, Kaiser M, Huber R, Ehrmann M. Protein quality control in the bacterial periplasm. Annu Rev Microbiol. 2011;65:149-68.

244. Krojer T, Sawa J, Schäfer E, Saibil HR, Ehrmann M, Clausen T. Structural basis for the regulated protease and chaperone function of DegP. Nature. 2008:453:885-90.

245. Humphrey W, Dalke A, Schulten K. VMD: visual molecular dynamics. J Mol Graph. 1996;14:33-8-27-8.

246. Silhavy TJ, Kahne D, Walker S. The bacterial cell envelope. Cold Spring Harb Perspect Biol. 2010;2:a000414-4.

247. Du D, Wang Z, James NR, Voss JE, Klimont E, Ohene-Agyei T, et al. Structure of the AcrAB-TolC multidrug efflux pump. Nature. 2014;509:512-5.

248. Matias VRF, Al-Amoudi A, Dubochet J, Beveridge TJ. Cryo-transmission electron microscopy of frozen-hydrated sections of Escherichia coli and Pseudomonas aeruginosa. J Bacteriol. 2003;185:6112-8. 